This item was submitted to Loughborough's Research Repository by the author.

Items in Figshare are protected by copyright, with all rights reserved, unless otherwise indicated.

\title{
Video and a sense of the invisible: approaching domestic energy consumption through the sensory home
}

PLEASE CITE THE PUBLISHED VERSION

http://dx.doi.org/10.5153/sro.2583

\section{PUBLISHER}

University of Surrey, the University of Stirling, the British Sociological Association and SAGE Publications Ltd. (c) Sociological Research Online

\section{VERSION}

AM (Accepted Manuscript)

\section{LICENCE}

CC BY-NC-ND 4.0

\section{REPOSITORY RECORD}

Pink, Sarah, and Kerstin Leder Mackley. 2019. "Video and a Sense of the Invisible: Approaching Domestic Energy Consumption Through the Sensory Home”. figshare. https://hdl.handle.net/2134/13471. 
This item was submitted to Loughborough's Institutional Repository (https://dspace.lboro.ac.uk/) by the author and is made available under the following Creative Commons Licence conditions.

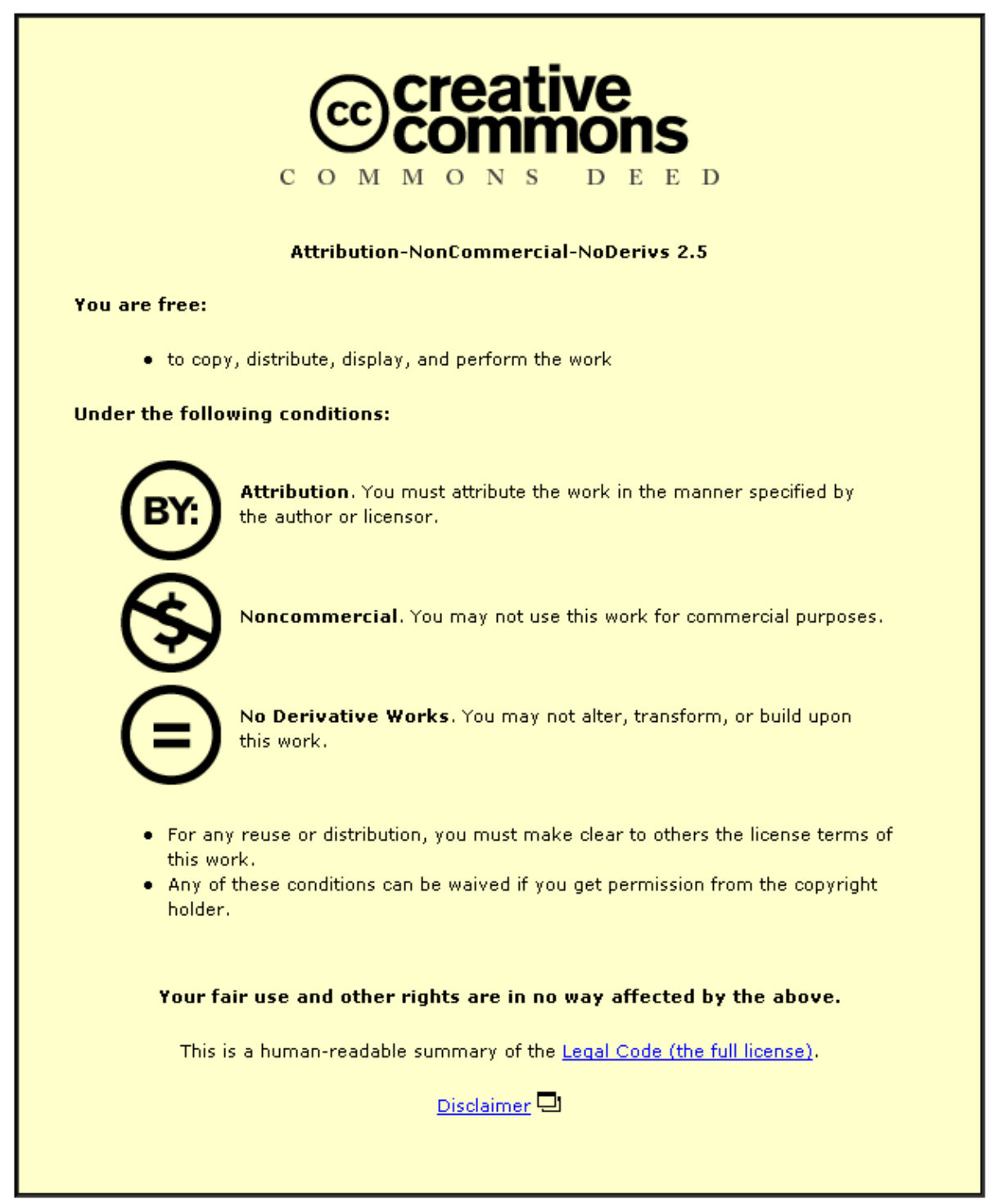

For the full text of this licence, please go to: http://creativecommons.org/licenses/by-nc-nd/2.5/ 


\title{
VIDEO AND A SENSE OF THE INVISIBLE: APPROACHING DOMESTIC ENERGY CONSUMPTION THROUGH THE SENSORY HOME
}

\author{
Sarah Pink and Kerstin Leder Mackley, Loughborough University, UK \\ Published in Sociological Research Online, 17(1)3, February 2012, \\ www.socresonline.org.uk/17/1/3.html
}

\begin{abstract}
This article proposes and demonstrates an approach to understanding everyday life that takes as its starting point the sensory aesthetics of place. In doing so it advances a video-ethnography approach to studying ‘invisible’ elements of everyday domestic life through the prism of the sensory home. Our concern is chiefly methodological: first, we take a biography of method approach to explain and identify the status of the research knowledge this approach can produce; second, we outline how the video tour as a multisensorial and collaborative research encounter can open up understandings of home as place-event; finally, we probe the status of video as ethnographic description by inviting the reader/viewer to access ways of knowing as they are inscribed in embedded clips, in relation to our written argument. To demonstrate this we discuss and embed clips from a pilot video tour developed as part of an interdisciplinary research project, seeking to understand domestic energy consumption as entangled in everyday practices, experiences and creativities.
\end{abstract}

\section{Keywords}

Sensory Ethnography, Place, Ecology of Home, Methodology, Qualitative Research, Energy Consumption, Invisibility, Video

\section{Prologue}

In the spring of 2011, Sarah set off for Rhodes' home - a four-bedroom house in a quiet area of an English town. Rhodes, who is a University Lecturer, had heard of our research from work colleagues and had volunteered for her family to be part of its pilot phase. She was working from home that afternoon, awaiting the arrival of her one-year old son who was being collected from nursery by her mother-in-law, and of course keeping some time aside for our project. Rhodes' husband, who is a teacher, was out at work. Their home is, like those of many home owners, at least in the UK (see Pink 2004), 'in progress'. They originally bought the house with the plan of extending and improving the property before selling it and moving on to their next project. Yet once their son was born they decided to stay, slowly completing the project of home as and when they could. This situation made for a home that was in part designed by its owners, for example to create a sensory experience that included the warmth of under floor heating in some rooms, carpets in others, soft lighting where it could be achieved, and music filtered across two of the downstairs rooms. In other ways, the house manifested a series of inconveniences and a sense of incompleteness as work remained to be done, decisions to be made. Again as is quite 
usual, these imperfections were lived with as part of the normal everyday. Indeed these details of the project of home all add up to make the contingencies of everyday domestic life. They collectively participate in how we experience and navigate home and, with particular relevance to our present research project, how and why we consume energy in the creation and maintenance of the sensory home.

Sarah's task was to develop the first collaborative video tour of Rhodes' home. The aim of the video tour is to move through the home (see also Pink 2004; 2006; 2007; 2009), following and discussing with the participant and, in doing so, to learn about the ways in which the sensory aesthetic of home is created. It involves particular attention to the textures, sounds, and the visual dimensions of home, how participants create atmosphere in their homes - as such, how they make their homes feel 'right' and what they do about it when someone or something messes this up. This focus is also an indirect way to begin to explore how people use energy in their homes (other techniques will be used later in the project). Although the participants in our work know very well that we are doing research about their energy consumption, and they are complicit in this task, through the video tour we seek to take the question of using energy out of the foreground. We thus seek to understand better what it is that participants do to make their homes feel right and, subsequently, to consider how they engage a range of energy sources in order to achieve this sensory aesthetic of home. We are thus interested in learning about energy consumption through the prism of the sensory home.

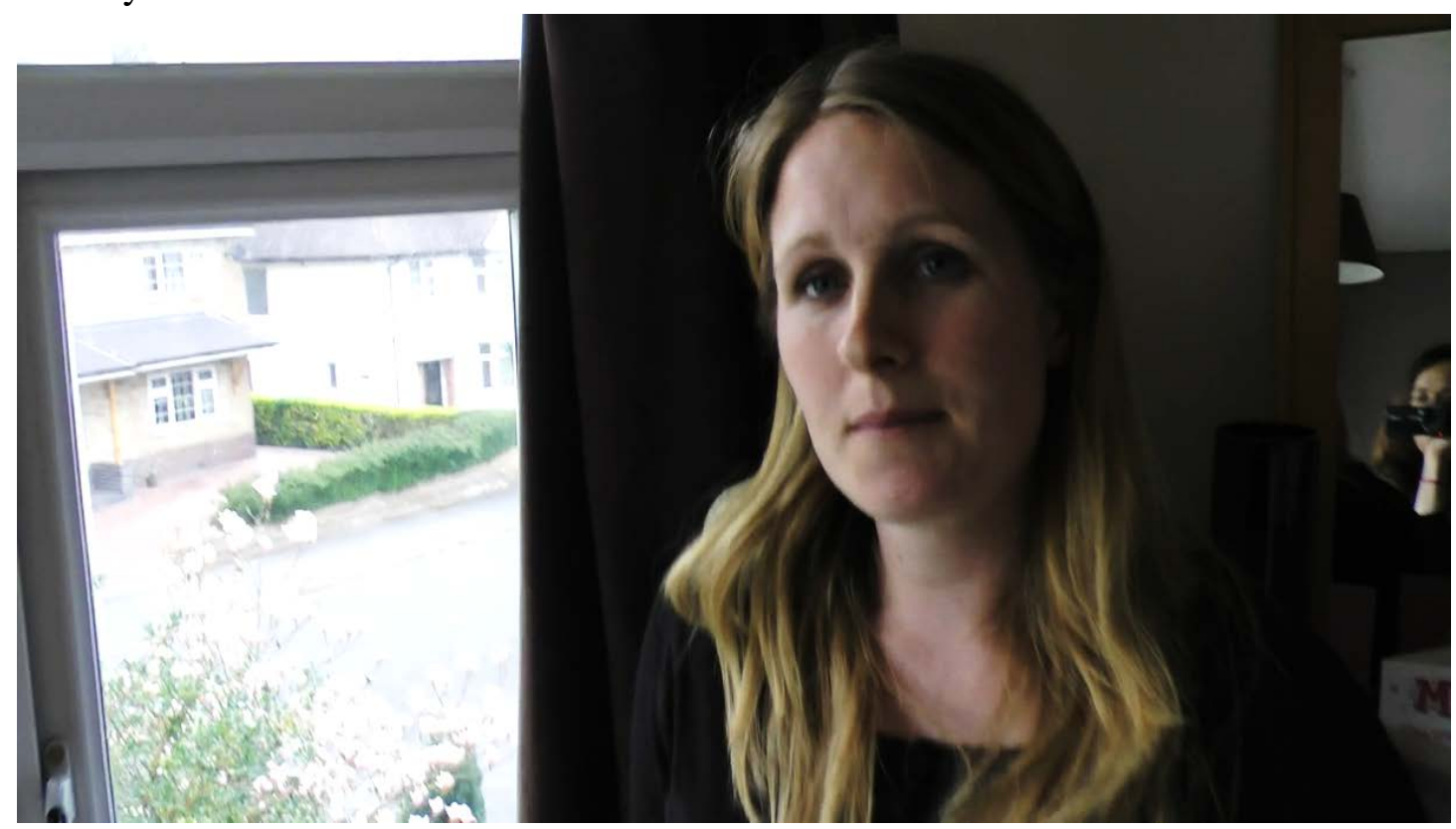

Figure 1: Screenshot of Sarah's collaborative video tour with Rhodes in April 2011.

(Note Sarah is reflected in the mirror, recording with the camera in the right-hand side of the image.) (c) LEEDR, Loughborough University, 2011.

Later, in the summer, Kerstin visited Rhodes to undertake the next stage of the video tour, a feedback meeting. Viewing the video with Rhodes formed part of our ethics procedure as well as inviting further reflections and insights. It gave Rhodes a chance 
to see how Sarah had caught her and her home on camera and, if necessary, to edit any footage she did not feel comfortable with. It also created a context for exploring further questions that had arisen for us when reviewing the tour. Moreover, during our subsequent audio-recorded conversation, Rhodes reflected on some of the changes that had occurred in the house post-video, again highlighting the transitional stage of the home and 'updating' the video tour to a current status. To some extent, watching the video made her see some spaces in a new light, thus prompting plans for future (mainly decorative) changes.

The follow-up was also an opportunity for Kerstin to add her own sensory experience of Rhodes' home to the knowledge she had previously gained through Sarah's collaborative video. This included feeling the breeze from the open kitchen doors into the garden, attending to the toddler's mealtime of beans on toast, seeing and hearing the living room play area 'in action', and sharing a cup of tea in the family's adjacent living space. What had been tidied and cleaned for the presentation of home to Sarah's camera was now more in line with everyday life; rooms felt busier and more lived in. At the same time, they were strangely familiar. Kerstin had visited this home before, 'through video', and had started to construct, along with Sarah and Rhodes' own reflections, a sense of place. ${ }^{\text {i }}$

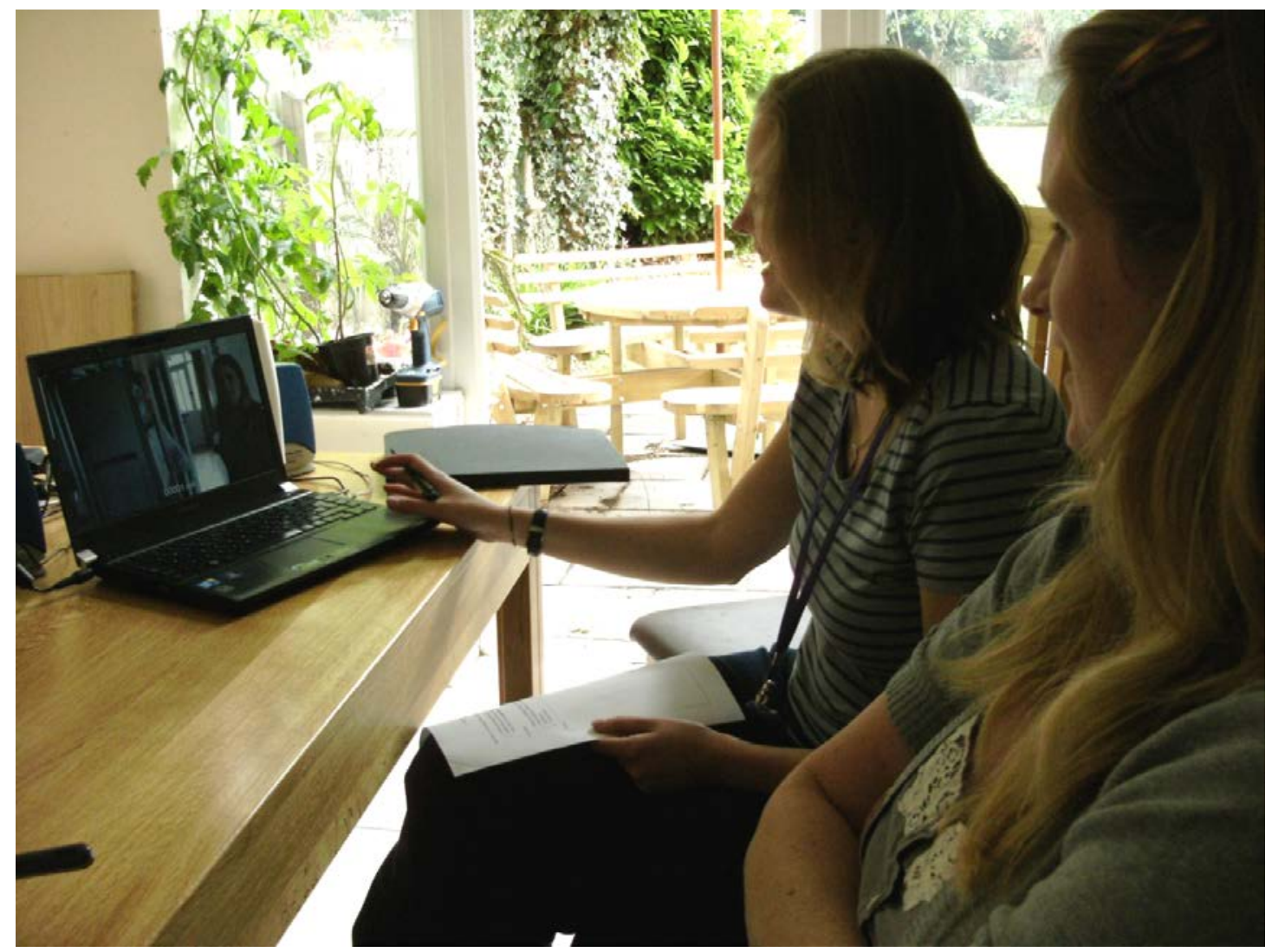

Figure 2: Rhodes revisiting her video tour with Kerstin in July 2011.

(C) LEEDR, Loughborough University, 2011. 


\section{Introduction}

In this article we argue that an understanding of the sensory aesthetic of home can provide an informative starting point for the analysis of everyday domestic life. In doing so, we build on earlier work to demonstrate how, as a method with a biography, the video tour produces a layer of knowledge about how the home is experienced and constituted. As such, the aims of this article are primarily methodological rather than empirical. Our focus is on the detail of the video tour as a route to knowledge rather than on presenting the findings of a wider study. We outline how this approach and method offer both a particular prism through which to understand home and a starting point for further investigations of a range of aspects of everyday life in the home. Using the pilot video tour as an example, we aim to demonstrate how taking the sensory aesthetics of place as a starting point for understanding everyday moralities, human and material agencies and practices can add a new dimension to the study of domestic energy consumption. Yet, we suggest such an approach has wider applicability in offering a basis for understanding the home as a material, sensory, social and experiential environment from which studies that have as their objectives an understanding of other dimensions of everyday domestic life might depart.

To situate our written discussion and the embedded video materials we trace the biography of the video tour method and the 'sensory home' approach employed here. This is important for two reasons. First, while existing forms of reflexivity often provide useful explanations of the biographies and positionality of researchers themselves, they are less frequently engaged to consider the processes through which methods and methodologies come about. Likewise in material culture studies the biographies of things are appreciated as central to the meanings associated with them (cf. Appadurai 1986; Riggins 1994; Hoskins 2006). With the currently increasing interest in methodological process and innovation (e.g. Wiles, Pain and Crow 2010, Bengry-Howell, Wiles, Nind and Crow 2011) and uses of digital technologies in research there is created a corresponding need to comprehend the implications of the biographies of methods and the technologies that form part of them for the qualities of research knowledge that they can potentially produce. Second, for research (such as ours) that has practical applications, such an appreciation can enable us to understand better the status and the qualities of the knowledge that our research produces and subsequently how it may be engaged for intervention processes. Attention to the biography of a method involves some summarising and reiteration of ideas presented in earlier works. This is developed in the following sections in order to both contextualise the understandings of the method and approach that we outline and show how they have been built cumulatively through the biography of the method. First, before proceeding with the discussion, we briefly introduce the earlier work from which these ideas and practices originated and outline how they are being applied in the LEEDR ethnography discussed below.

Sarah Pink developed the notion of the sensory home (2004) on the basis of consumer video ethnography research focusing on homes in the UK and Spain. Building on 
Daniel Miller's (e.g. 2001) material culture approach to the home, she argued that the making and experience of the home as a multisensory environment was likewise integral to how self-identities are constituted through everyday life practices. Video tours of the home were central to this research approach, which involved studying how people experienced, made and maintained home, both through the tour and the performance of an everyday routine domestic task (the methods and findings are discussed in e.g. Pink 2004; 2007; 2009; 2012). The version of the video tour explored below, and undertaken 12 years later, develops its earlier articulation in two key ways.

The first development lies in the wider contextualisation and empirical focus of the tour. In the example discussed here the method is focused specifically (although indirectly) on understanding domestic energy consumption within an interdisciplinary research and intervention project, lasting over three and half years. Thus situating the method and the demands made of it, within a more extensive and longer-term engagement with the homes and lives of participants than in previous work. Therefore our video tours are informed by and inform (both for researchers and participants) other research exercises/encounters undertaken by our own Social Science team and the Engineering and Design research teams.

A second development relates to research design. The notion of the sensory home was an outcome of the research knowledge produced through a first analysis of an earlier video tour study (Pink 2004). The idea that the home is a sensory environment can be applied to homes across cultures and social and economic classes. There is no case for suggesting that one home is more sensory than another. Rather the specificity relates to how the sensory home is constituted and experienced. Through a second analytical process, worked though theories of place, Pink built on this idea to reflect on how the movement of persons and things in domestic processes as part of the sensory home implicate energy consumption (Pink 2012). The analysis and re-analysis of the earlier research has been further developed through methodological thinking around the video tour and the nature of the knowledge it can produce and communicate (e.g. Pink 2007, 2009, 2011a 2011b). These three developments have been essential to the research design used in the tour discussed in this article.

In the following sections we therefore first situate the video tour method and approach within the context of energy studies, proposing how it may be engaged in a new research context, currently dominated by other approaches. Therefore, although the focus of this article is chiefly methodological, we approach the discussion of the method by examination of its potential within a specific ethnographic research context in order to illustrate through example the kinds of detailed ethnographic knowledge the video tour method can contribute and how this might be used. Second we examine the methodological principles that inform our present use of the method. We ask how video might be engaged for exploring 'invisible' dimensions of everyday life, which may include flows like smell, sound, electricity, or gas, but moreover how it might 
become a medium for the description and inscription of the experiences associated with them. Third, this latter task is carried through as we draw from our research about domestic energy consumption, using written description with embedded video clips to demonstrate how this approach has been engaged in practice, and to invite readers/viewers to engage with it. Yet, like any approach, ours offers a theoretical and practical entry point for understanding the sensory ecology of home, but does not necessarily answer all the questions we may want to ask. Therefore we end by suggesting how it may simultaneously serve as a prism for opening up ways of knowing about the home that create new avenues for investigation.

\section{Approaches to understanding domestic energy consumption: research context}

The video tour example discussed in this article was developed as part of a pilot phase undertaken to inform the ethnographic component of an interdisciplinary EPSRCfunded research project: Lower Effort Energy Demand Reduction (LEEDR) (20102014; www.leedr-project.co.uk). With a specific focus on the opportunities offered by digital interventions, LEEDR aims to enable householders to reduce their consumption of energy in ways appropriate to their everyday lives. The video tour methodology is used across our sample of twenty family households who have been recruited through local advertising (posters, radio, press), notices in work and community group newsletters, and via snowballing. Due to technical aspects relating to longitudinal energy monitoring procedures, participation is restricted to owneroccupied properties. Although this influences the composition of the sample in terms of the economic status of participants to some extent, we have been able to include differently situated families in terms of their levels of income and education and priorities. 


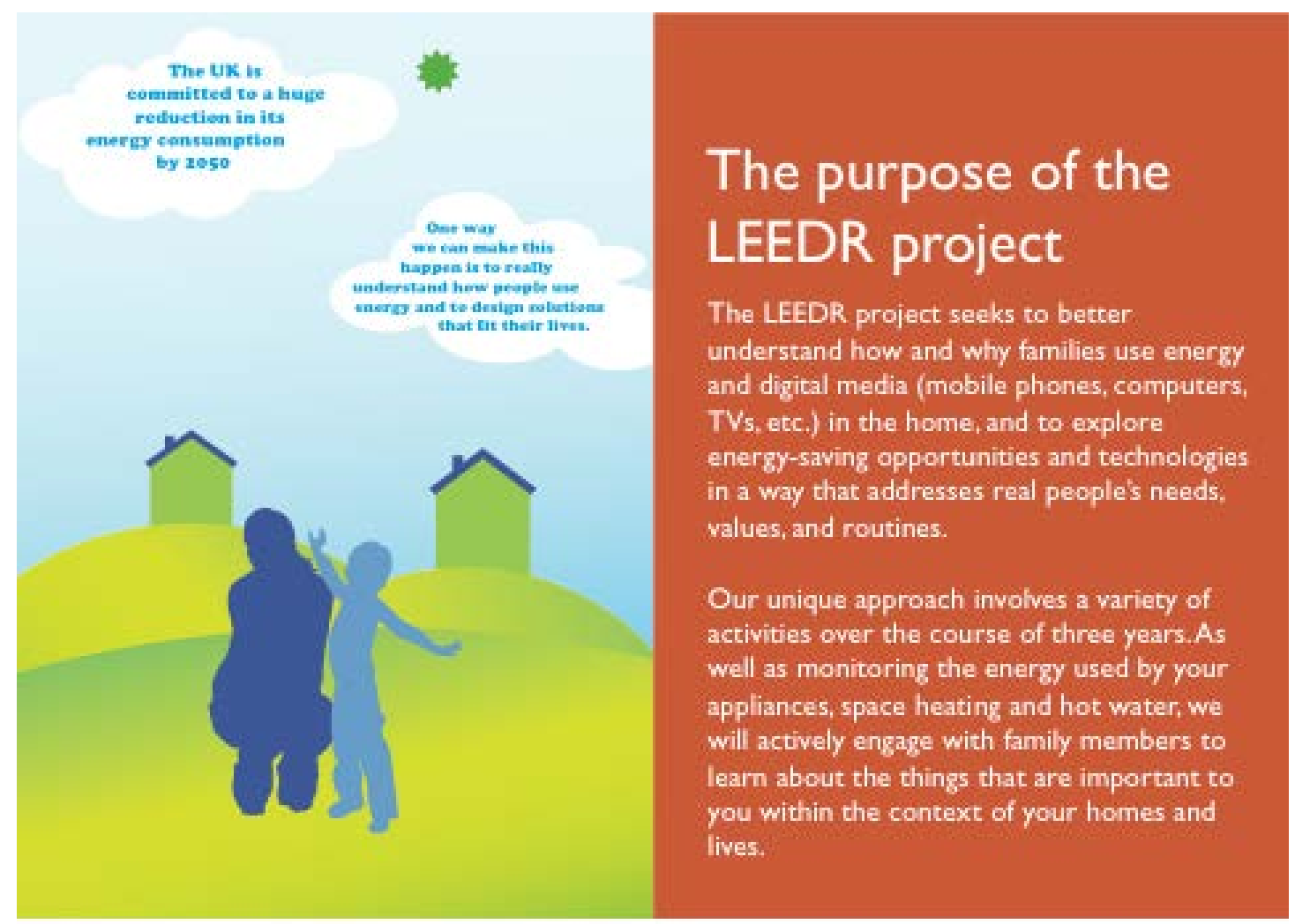

Figure 3: The LEEDR project as explained to participants in our information pack. Online at http://leedr-project.co.uk/pdf/Booklet-Combined\%20Read.pdf

(C) LEEDR, Loughborough University, 2011.

The first stage of LEEDR's ethnographic strand seeks to develop an understanding of how our sample of households already live and consume energy in their homes, and of their digital media practices as they also extend outside the domestic sphere. To achieve this, we focus on the sensory aesthetics of the home first (through the video tour), followed by a focus on a series of selected interrelated everyday life and digital media practices. The findings of this work, in combination with qualitative research undertaken by the Design team and technical measurements based on energy monitoring research carried out by the Engineering team, will be used to inform the development of digital design interventions. Later, a second stage of our ethnographic work will explore the implementation and application of LEEDR's technological interventions in participant households.

Our research is also situated by the growing field of energy studies in the social sciences where approaches to understanding domestic energy consumption rooted in sociology and anthropology have tended to agree that rather than researching energy use per se, the focus should be indirect. Energy itself is an invisible flow (Lutzenhiser et al. 2009 and see Pink 2011b), it is sourced through sockets and appliances and it is engaged to achieve various objectives in domestic life rather than being consumed as an isolated artefact in its own right. Therefore, as the anthropologist Harold Wilhite has expressed it, 'people do not consume energy per se, but rather the things energy makes possible, such as light, clean clothes, travel, refrigeration and so on' (Wilhite 
2005: 2). Sociological studies of energy consumption in homes have been informed by Alan Warde’s (2005) interpretation of practice theory as developed by philosophers such as Theodore Schatzki and Andreas Reckwitz. This approach creates a route through which sociologists of energy consumption can approach the question indirectly by researching not energy but the 'enmeshed [...] network of related practices and habits' (Shove and Warde 2002: 246) through which people consume energy (see also Shove 2003; Gram-Hanssen 2008; 2011).

The practice approach assumes a theoretical commitment to placing practices at the centre of the analysis, and indeed affording them analytical privilege since, following the logic of a practice approach, as Schatzki puts it, 'practices are the source and carriers of meaning, language and normativity’ (2001: 12). The advantage of this is to facilitate understandings of how energy consumption is located in everyday routines, habitual ways of doing things and the social norms that inform them. Yet placing practice at centre of the analysis tells us little about either individual variation or the multisensory, social and material environments of which practices are a part (as Pink argues in more detail elsewhere (Pink 2012)). In a future article we intend to reflect on how detailed practice studies might cohere with the video method tour we discuss here. For the present discussion, however, we focus on the question of how an approach that gives analytical privilege to the sensory aesthetic of home offers an alternative starting point. Thus rather than privileging what Warde describes as the 'point of view of a theory of practice', whereby 'Consumption occurs within and for the sake of practices. Items consumed are put to use in the course of engaging in particular practices' (Warde 2005: 146), instead, we begin by asking how the sensory aesthetic of home (and of course the materiality this presupposes) is experienced, produced and maintained, and how practices and energy are 'put to use' to achieve this.

We would note here that the notion of the sensory aesthetic of home does not assume a judgement of value or taste. Rather it refers to the home as a multisensory environment, and to how people experience, interpret and negotiate their homes through the senses. Thus every home has a shifting sensory aesthetic which both shapes and is an outcome of the routines and practices of its inhabitants (see also Pink 2006; 2009). While life style choices, social expectations and economic constraints will play a role in the kind of sensory aesthetics people aspire to or achieve, our research does not presuppose any external measure of aesthetic attractiveness. Nor do we assume that participants' own measures of the sensory aesthetic of their home are constant or uncontested. They might change depending how members of the household of different gender, age and generation move in, through and out of the home, on the time of day, on the changing uses of areas of the home, and so on.

Our analytical priority is the place-event of home. As Pink has outlined elsewhere (e.g. 2009; 2011a; 2011b; 2012) there are (at least) two ways of articulating a theory of place, we briefly reiterate these points here to contextualise the discussion. The 
first is abstract. Here we follow Doreen Massey's notion of 'the event of place' (2005: 150) as 'an ever-shifting constellation of trajectories', which is both open and temporal (2005: 151), and Tim Ingold's understanding of place as 'unbounded' and an entanglement of lines (e.g. 2007; 2008). These notions of interweaving processes and entanglements we argue, offers a way to understand how the processes, things and persons of home become interrelated to make the home as a place event. This creates a theoretical context for understanding the video tour as both a process that becomes interwoven with others in the place event of home, and one of the entangled lines of the 'meshwork' (Ingold 2008) that is the home at anyone moment. Understanding the home and the tour through it as such, offers routes through which to 'unpick' some of these relationships. Second, we work with an idea of place making (which is current in a number of literatures across the social sciences and humanities, discussed e.g. in Pink 2009; 2012). Here, the human subject is put at the centre of the analysis and is understood as 'pulling together' and shaping the material, sensory and social elements that create a particular interpretation and experience of place. This approach assumes a certain role for human agency and indeed extends this agency to the reflexive analysis of the role of the researcher in the making of 'ethnographic places' (Pink 2009). Touring with video creates an ideal opportunity to chart this process, in that both a route around the home and the route of the researcher through the environment of the home are inscribed (Pink 2011a) in the video recording.

The focus of the video tour and the understanding of place with which it engages is therefore based on the relationality between the persons, things and processes (owed to the work of Massey 2005; Ingold 2008) that compose the home. It provides a route to understanding how the home is constituted, how it changes, and how it is experienced as well as of the place of the researcher within this process.

\section{Principles for knowing, learning and viewing video recordings of the invisible}

Video is widely used in participatory research (see Pink 2007, Chalfen and Rich 2007, Lammer 2007, Mitchell 2011) and the potential of video to acknowledge and explore sensory experience beyond the audiovisual is increasingly recognized in visual anthropology practices of research and representation (e.g. MacDougall 2006, Pink 2006, 2009 and the journal Sensate). Rooted in theories of the interconnected senses emerging from phenomenological anthropology (e.g. Ingold 2000), and in relation to film (MacDougall 1998), we understand video as a route through which seeing and hearing can lead researchers and viewers to empathize with and imagine multisensory embodied experiences and not simply the aural and visual worlds of others (see also Pink 2009). Therefore we might understand video recordings in terms of MacDougall's point that 'visual media allow us to construct knowledge not by “description" [...] but by a form of "acquaintance”" (2006: 220). In the context of our project, forms of acquaintance might include both the idea of feeling that we understand something because we can access it through a similar personal memory or experience, or conversely by seeking to use our own resources of experience to try to 
understand that which is quite different to our own. We might think of this in terms of three issues: what the researcher can learn though using video as part of the research encounter; how researchers might understand and engage with the video recordings themselves; and the positioning of the viewer in relation to video as ethnographic description.

In earlier work exploring self-identity through the sensory home, Pink noted how 'To represent their self-identities informants employed multiple sensory modes: music, images, smell, and touch' enabling them to 'represent their lives in their homes through knowledge that was neither exclusively visual nor verbal' (Pink 2006: 63). Video invites participants to perform their sensory embodied ways of knowing in and engaging with their homes. In this way we might see it as offering us a route through which to comprehend the embodied positioning of participants in their sensory homes, which goes beyond the ways these experiences may subsequently be expressed verbally through culturally constructed (in our case modern western) sensory categories.

Video may also be seen as a reflexive research tool, and understood in relation to the recording position of the researcher. In this sense video generates what the ethnographic filmmaker MacDougall calls 'corporeal images' in that the images 'are not just the images of other bodies; they are also images of the body behind the camera and its relations with the world' (2006: 3). In our current work we shift the research focus from self-identity to the question of energy consumption. Our interest in embodied sensory knowing in the home is re-focused to explore/experience with the camera and our own bodies how participants sense and create a sensory aesthetics of home and, in doing so, how they create a demand for energy. For instance, during Rhodes' tour both Sarah and Rhodes experienced and talked about the floor surfaces they walked over. This involved the feel underfoot, sound and visual experience of the floors, along with Rhodes' explanations of how they were cleaned. Thus the video was produced through a process that involved experiencing surfaces that required energy consumption to maintain their sensory and material forms. In this sense we might view the video as an ethnographic description of a context that had as one of its constituents a sensory/material surface that both creates the demand for energy consumption and is the outcome of energy consumption. When we view this video seeing floor surfaces through the camera lens represents the embodied vision of the researcher who is holding the camera and standing on, feeling, hearing and sensing that floor. This does not give the viewer a direct multisensory experience of the same floor surface. However it does invite the viewer to empathetically imagine her or himself into the experience that is suggested by the video sequence, and thus into the sensory aesthetic of the place event of home that is being generated by the playing of the video tour. Connecting this to energy consumption, this invites the viewer to imagine the experiential context that the researcher and participants inhabited and that was created through a process that has involved the consumption of energy. Thus video can be seen as a route to learning about, experiencing and representing the 
visible, material and sensory manifestations of energy consumption. However, these principles also require a certain commitment on the behalf of viewers to take on the viewing position that generates such ways of knowing and learning.

Indeed, video may be viewed as generative of new ways of knowing for researchers and audiences. The video tour is not simply a recording of the home and people in it but a recording of the researcher's body moving forward through a multisensory and social environment. This includes, for instance, moving through changes in temperature, sound levels, smells and textures. Elsewhere, through an example of walking out of doors, Pink has built on Ingold's argument to suggest how walking with video can be understood as a form of inscription and description:

As Ingold points out, walking is not simply about making impressions on the ground, since 'as we walk the ground we also breathe the air' (2010b: 116). In the air we do not make even a momentary impression - or at least, no visible impression, although our scent and breath may well remain behind us as we move on. Because ... the process of walking with video is one of going forward through rather than mapping onto an environment, it offers a very particular way of creating a permanent trace of the routes we take through both the ground and the air. Moreover it provides a way of describing this trace and the experience of making it. (Pink 2011a: 146)

The same principle can be applied to video recording indoors. If both the ground and the air are part of the experience of the environment that we are seeking to understand (as they indeed are in the study of the sensory aesthetic of home where we are interested in floor surfaces, smells and temperatures), video creates a trace of our routes through that sensory environment. Video of course does not record invisible elements like smell, warm or cold air or the feel of the carpet or wooden floor. Yet in recording what is said about it, facial and bodily expressions and performance, the sound of footsteps and visible and spoken referents, it has the potential to invoke empathetic responses to these experiences. To view video recording as such - that is as a trace through the home inscribed on video - we therefore invite our readers to adjust their positioning as viewers. Video as presented here is neither documentary film nor documentary evidence. We propose that the video clips should be understood as the outcomes of routes through as a multisensory environment that the researcher and camera moved forward through. In this sense, when viewing the video clips we ask viewers to think of them as clips taken from the movement of the camera forward through the home, rather than as distanced images of the home. Therefore we think of playing video forward as a way to invite the viewer to travel forward with it, and to add their own empathetic interpretations to the trace of the route through the home it stands for.

Our presentation of video in this article is interwoven with a written discussion and is intended to therefore work on various levels to: bring the corporeal positioning of 
researcher and participant and the sensory ways of knowing that cannot be directly translated into written words to our discussion; invite viewers to engage empathetically with the embodied sensory experiences of researcher and participant, to imagine, based on their own experiences the experience of the environment as it is inscribed in the video; and invite viewers to 'move' with the video as it is played forward through the environment of the home, and to add their own interpretations. Viewers' own experiences may not correspond exactly with what they imagine those of the researcher and participant to be. They might vary, for instance in relation to biography, gender, generation, class and more. However our aim is not to simply suggest that correspondences of sameness may create meaning. But rather to offer an opportunity for viewers to develop a sensory embodied engagement with the materials and, as such, to use such familiarities and discrepancies as routes to emplaced knowing, imagining and forms of understanding.

\section{Experiencing place with video}

In the prologue, we introduced Rhodes' home as a place 'in progress'. Large-scale structural work, a two-storey extension, had been completed and housed a new living room and utility space with cloak room downstairs, and a master bedroom, Jack and Jill en-suite and nursery extension upstairs. At the same time, there were plans for further refurbishment - the old front lounge, one of the spare bedrooms - as well as for finishing touches around the house, such as pictures, vases and lamps. Rhodes' video tour was often structured by the history of the house - past, present, future and demonstrated much personal investment in designing and contributing to its look and feel: the extension was based on Rhodes' measurements, her mother's paintings were hung on the downstairs walls, and her son's bedroom included reclaimed furniture which she and her husband had personally restored. The tour was also inevitably framed by Rhodes' energy awareness and her understanding of the aspects of the home that may be relevant to our study. For example, at the beginning of the tour, Rhodes introduces the family's favourite area of the home, the new living room area in the ground floor extension, drawing attention to the separate heating system and underlining the family's use of low-energy bulbs. These framings also underline the idea of the home as an experiential environment - as Sarah moved through rooms with the camera she experienced wall decorations, floor surfaces, lighting systems and air temperatures, and learned about their affective meanings. Yet these sensory, material and technological manifestations were simultaneously part of how Rhodes and family subscribe to an energy-conscious way of living and aim to reduce energy consumption.

\section{The compromises and contingencies of sensory aesthetics and energy saving}

Homes are not necessarily perfect renderings of the interface between sensory aesthetics and energy consumption. As we outline in this section and continue to reflect on in later examples, the video tour enabled us to understand how constraints regarding sensory aims, financial considerations, material contexts and practicalities mean that compromises and temporary fixes - regarding both the sensory aesthetics 
of home and energy consumption - are part of the way that the home as sensory place event is experienced and made.

These issues became clear at the beginning of the tour in the new living room, which Rhodes described as the area where the family spends most of their time at home. The following clip introduces the living room inviting the viewer to engage with the context of the encounter as experienced through the camera and created through light, colour, space, sounds, and visible textures, as well as through Rhodes' words and gestures.

CLIP 1: Introducing the living room. (C) LEEDR, Loughborough University, 2011.

To contextualise this clip in relation to what matters for our research, we now explain how it offers us a route to understanding energy consumption. We can see and are actively shown things and spaces; we hear Sarah's steps on the laminate floor, the creak of the TV cupboard as it is opened to reveal the stereo system; we can imagine the warmth and texture of the bean bags and rug in winter and, although it seems a relatively cloudy day, of the sun shining through the folding doors to allow the drying of clothes in summer. Rhodes also describes how the sounds of music and nursery rhymes filter through living room and kitchen, and the ways in which toys spread across the floor change the materiality and uses of the space. As a researcher being there in the room Sarah was therefore invited to imagine how the room would be sensorially transformed in these different ways, and what this would feel like. What we see in the camera represents something of this experience as it is moved to seek the visible manifestations of these multisensory experiences and to attend to Rhodes' own movement. We also learn about Rhodes' sensory ambitions for the room, that is, about how she imagines its future. In this sense showing how the video tour can become a template for participants' own imagining, inviting researcher and viewer to join them in this. It reaffirms our point that the home is a place event in progress. In the case of the clip presented, this is shown as Rhodes discusses how the long term aim is to create softer lighting with floor and table lamps, while the temporary arrangement depends on brighter light from ceiling lamps (which they chose for future home owners) and existing floor lamps (which they did not choose at all). In fact, lighting is an on-going project around the house through which aesthetic and energy-saving processes become intertwined in ways that are contingent and embedded in other social, material, affective and practical elements of everyday life.

Thus by touring the room on video (as researcher and viewer) we begin to learn how Rhodes' sensory-aesthetic aims for the room (both in everyday use and in the future) are contingent on a range of elements including affective, material, technological, historical, practical and environmental factors. It is here that we also learn how a sensed and embodied understanding of place (its properties, arrangements and possibilities) and affective moralities (e.g. parental responsibilities) are intertwined with the ways in which energy uses and saving measures are realised. From this 
starting point we can understand how these processes are part of the environment in and for which everyday practices are harnessed, and how they in part determine the specificities of the way practices are performed. Through the video tour we explored the sensory experience of each room and, in doing so, were able to track the ways that these experiential qualities created the contingencies for domestic processes. For instance, in the living room we also learned how the ways laundry is dried are contingent on how sensed 'inadvertent' heat is harnessed both in the living room (the sun shine) and, as we are told when we were later in the adjacent utility room, through the positioning of the under floor pipes leading into the living room, which has the unintended but useful side effect of drying clothes more quickly. Existing or created heat sources are thus sensed and appropriated around the house where possible. For Rhodes this process also formed part of the way that priorities were negotiated in the creation of the sensory aesthetic of home. Rhodes told us 'I hate clothes being in front of [the living room doors into the garden]'; yet she put them there as her sensory knowledge of the home told her that they would dry well, even if her ambitions for the sensory aesthetic of home were thwarted.

Therefore by seeing each room as the outcome (albeit shifting and in process) of these contingencies and negotiations, we can thus use it as our starting point for understanding the environments that energy is harnessed to create and maintain.

\section{Making home feel right: sensing floor surfaces and temperatures}

Our focus on the sensory aesthetics of home aims in part to explore what makes the home 'feel right' for participants and how energy is engaged in this process. One good example of this is the experience of floor surfaces, how they are selected and how the sensory, affective and moral qualities associated with them are maintained. The sensory embodied experience of the home feeling a particular way is also affective and moral and as we learnt while discussing the floor underfoot, the surfaces that Sarah experienced were the outcome of a combination of these strands. Since becoming a parent, Rhodes started to use a traditional and well-known cleaning product around the house because, as she later told Sarah, 'it's the best thing for Oscar'. It is 'well known in the baby world', 'one of those trusted brands' (follow-up interview). Energy is also harnessed in this process: Rhodes uses boiled water from the kettle to ensure sterilization, which is also helped by the spatial arrangement of the home given that the living room is connected to the kitchen. We encountered the boiled water practice in a second video pilot, with the participant additionally commenting on its practical advantages: the hotter the water, the more quickly the floor dries after cleaning (thus reducing the risk of damage), and the easier it is to put furniture back into place. The pilot tour also showed us how floor surfaces more widely play an interesting role in determining how energy is consumed. As we explored Rhodes' upstairs rooms, we learned that some of these were carpeted in order to create a particular underfoot experience. The toddler's room, which had originally been designed as a guest room had a carpeted floor to make it comfortable for guests (whereas had it been intended as a child's room it would have had a 
laminate floor for easy cleaning). Again this implied a specific form of energy use in this case using the vacuum cleaner, to maintain its sensory qualities. Exploring these details with participants thus showed us during the tours how spatial arrangements, moral discourses and idiosyncratic theories of cleanliness can shape how energy use is implicated in the making of place that feels clean and is also appropriate to particular floor surfaces that have either been selected for their particular sensory and material qualities, or have such qualities that participants wanted to maintain. A focus on the home as sensory place event therefore invites us to consider how practices that involve energy consumption are engaged in the achievement of this, and the ways in which these practices are shaped by the moral and material elements of home.

A second and perhaps more obvious way in which invisible energy use was implicated in the creation of a sensory environment was through the heating system. As we toured with the camera we passed through the very environments that flows of warmth and coldness were associated with. These flows and variations were connected with understandings of the materiality and heat qualities of each room along with ways of knowing about temperature that were both based on practical articulated knowledge, experiential categories and ways of thinking about this in terms of saving energy. This is best demonstrated in the older part of the house, which unlike the new lounge does not have under floor heating. By exploring the old lounge with the camera we found that a series of technological, spatial and material qualities associated with it were connected to the development of particular sensory-affective experiences in it, which place demands on energy consuming practices. Because the cable TV connection is in the old living room it is the only place where the full range of weekend sports can be viewed. It is heated by a radiator, as well as having a fireplace, yet it was identified as a badly insulated part of the house, which gets much colder than other spaces. In order for Rhodes' husband to watch TV sports in winter the regular heating system as well as an open fire was often needed.

As our next clip shows, video enables engagements with the way sensory environments are heated by enabling us to understand better the embodied, material spatial and aesthetic elements of these contexts where tacit knowing is enacted and therefore has implications for energy consumption. For example, in the hallway, the lack of insulation, choice of front door, location of the thermostat and Rhodes' embodied knowledge create other contingencies for the way energy is used to heat the home.

CLIP 2: Hallway (C) LEEDR, Loughborough University, 2011.

The video context invited Rhodes' visual and tactile engagement with the space around her, thus allowing us to appreciate the aesthetics of the front door and the thermal curtains, imagine the feel of the cold through her fingers, and comprehend the spatial proximity between entrance and thermostat. Thus we learn how feeling the 
cold from the entrances, knowing that heat rises to the top floors and, in this case, the transferral of understanding 18 degrees as the right temperature based on experiences at their previous home (follow-up interview), are implicated in the sensing and making of home. The thermostat settings are a complex negotiation of spatial arrangements and fixes, and embodied and learned knowledge. These elements along with financial decisions relating to not building a porch show very well how material, technological and human agencies intersect in the making of the sensory place event of home and in determining how (and how much) energy is consumed in these processes.

\section{The sensory home and the interweaving of processes}

Our emphasis in this article is not on identifying how energy is consumed through practices so much as on examining what Massey (2005) calls the 'constellations of processes' of home and how to access these through research encounters. However because everyday practices are inextricable from these processes the video tour offered us a way of identifying the material and sensory home as made through and shaping multiple and interwoven domestic practices. Thus it gives us a starting point from which to understand how practices are enacted in relation to the contingencies of the sensory home, and to consider practices as relational (something we will take up in future work). The final clip we share was filmed at the end of the video tour when Sarah asked Rhodes to re-enact some basic routines. We were interested in tracing Rhodes' paths through the house during mundane but significant everyday moments, like going to bed, getting up in the morning, leaving and returning home. We focus on the bedtime routine, starting in the hallway. (Note the sounds filtering through from the living room.)

\section{CLIP 3: Night time routine (C) LEEDR, Loughborough University}

The bedtime routine is accompanied by a hot drink (using the kettle), the starting of the dishwasher (derived from a socio-technical/-economic context, now habitually carried on), the shower (hot water), and the sound of the television as background noise whilst getting ready for settling into bed. What is fascinating to us, and was arguably accessed precisely because Sarah and Rhodes actively traced the bedtime routine, is the way in which contingent factors again drive the use of energy in the home. The timer on the washing machine is broken and, in any case, its new position underneath the toddler's bedroom prohibits the washing machine's nocturnal use. This puts into context what we had learned in two earlier stages of the tour, enabling us to see how energy consumption needs to be understood in terms of an ecology of home: when touring the toddler's room we explored how its sensory environment was made at bedtime, using a combination of black-out blinds and indoor lighting; and in the utility room we had explored how the relatively hidden position of the washing machine in the utility room means that laundry can be forgotten and only discovered when someone passes through on the way to the cloakroom, or to fetch their coats or shoes. In both these moments of the video tour energy use was implied: in the 
toddler's bedroom to create the sensory aesthetic of bedtime; and in the utility room to re-run the machine wash if it had been left too long. This enables us to understand how energy consumption or saving is partly contingent on two factors that might at first glance not seem to be related: the priority given to the toddler's bedtime environment prohibits a night time low cost energy laundry routine, and the spatial arrangement of the home and location of the boiler, plumbing and washing machine mean that laundry cycles might be repeated.

The bedtime enactment was indeed rich in showing how energy consumption is bound up in compromises, contingencies and the home in progress. Our second point is demonstrated through a focus on how the spotlights were used at bedtime because nobody had had a chance to change the bulb on the bedside lamp; and the position of the TV set and the couple's preference of drifting into sleep with the timed television (digital radio) as a bedtime soundscape meant that at least one appliance in the house remained on standby all night, being switched off at the socket as part of the early morning routine. Again, we see how the making of a particular sensory experience of home demanded practices that harnessed energy consumption.

Above we have gone into detail to show how by focusing on such idiosyncratic events and habits in one household, can reveal something of the relationality between the things and processes of the home through which energy is consumed. In our research the video tour of the home enables us to explore, experience and record the details of how they are embedded in the sensory aesthetic of home. We should note that our description of the video tour, what we could learn from it and the follow-up interview, has been co-written. It stands for a merging of the first-hand experience and the viewer-researcher perspective. It is to this that we invite viewers/readers to add their own interpretations.

The implication of revealing the contingency of the ways energy is consumed is not a call for a dead-end focus on the endlessness of individual variation. Yet it does call for us to consider the question of how, in the ongoing process of making and remaking the sensory home, practices and habits become constituted and embedded in a continually renegotiated relationality with the persons, things and sensations that form part of the ecology of home. Thus opening up an avenue for our own (and we hope others') future consideration.

\section{Conclusion}

In this article we have outlined how the sensory-ethnographic video tour can provide a route into exploring some of the less visible dimensions of everyday life. It is of course not our claim that the video tour provides a complete set of answers to research problems centred on the home. Rather it has been our aim to suggest how it can serve as a practical and analytical entry point for understanding aspects of everyday life in homes. We have shown how, in the case of our own project, the video tour has enabled us to understand how domestic energy is engaged for the production and 
maintenance of the sensory home. By sharing embedded videos we have invited readers/viewers to form their own knowledge of the sensory and 'sociocultural texture' (Sunderland and Denny 2007: 270) of the home and of the performances and words of our research participant; thus to develop this knowledge in relation to our written argument as well as 'by a form of "acquaintance”' (MacDougall 2006: 220) with what is seen and heard and felt on screen.

In analysing our video tours, we find it useful to think of energy use as manifested in and contingent to flows of, for example, warm or cold air or water, the sounds of music playing or the way the floor feels underfoot. The precise ways that energy is consumed by householders are based on the embodied experiences and ways of knowing of social individuals as well as their active sensory-aesthetic making of home. The video tour provides a starting point or route to knowledge that enables us to understand the home in an abstract sense as an event of place, and simultaneously as an experiential place. Above we have shown how, in the case of researching domestic energy consumption, it creates a novel way of seeking to understand how the specificity of the ways energy is consumed emerges from the uniqueness of the event of place. It also begins to indicate to us where we should start looking to determine the relationality of the practices that are engaged in the making of home. This leads us to our next research task which involves a focus on how energy is consumed through specific everyday life 'practices'.

To comment briefly on the wider implications of this approach for researching the home, we return to our opening discussion. In this research the notion of the sensory home forms an analytical starting point, rather than emerging as a research finding (as it did in earlier work (Pink 2004)). The work of this article has been to frame our current research practice in relation to the ideas developed in earlier work and to demonstrate how video tour method informed by a theory of the place-event of home and engaged as a means of exploring the sensory aesthetic of home can offer a route to knowledge about a new applied research question. It is our hope to have extended earlier arguments to demonstrate a series of novel points. First by thinking in terms of biographies of methods and tracing their development, we can make their theoretical and methodological positioning explicit. This allows us to reveal how such a trajectory has informed our current understanding of the potential of this method as a route to knowledge, as well as create consistency between the ways theoretical ideas are used to understand research process and research findings. Second we have demonstrated how the method has been developed and applied in a new context, relating to energy research. In doing so, we have shown how the method operated as a specific route to particular types of research knowledge, while also suggesting that the approach may be applied to other research problems. Taking the sensory aesthetic of the home as a starting point, we suggest, can be seen as a prism through which to understand the multiple processes through which home is constituted. Finally through the embedded video recordings we have opened up an arena through which the detail of how the video was produced and the possibilities through which both we and other 
viewers might engage with it might be appreciated and critiqued, and we welcome further debate on this question.

\section{Acknowledgements}

The interdisciplinary LEEDR project, based at Loughborough University, is jointly funded by the UK Research Councils’ Digital Economy and Energy programmes (grant number EP/I000267/1). For further information about the project, collaborating research groups and industrial partners, please visit www.leedr-project.co.uk. The authors would like to thank all the households who have generously participated in this research. In the case of this article, we particularly thank Rhodes for her participation and for giving her time to read this article before publication. We are grateful to John O’Brien for lending audio-visual support.

\section{References}

APPADURAI, A. (Ed.) (1986) The Social Life of Things: Commodities in Cultural Perspective. Cambridge: Cambridge University Press.

BENGRY-HOWELL, A., WILES, R., NIND, M. \& CROW, G. (2011) A Review of the Academic Impact of Three Methodological Innovations: Netnography, Child-Led Research and Creative Research Methods. NCRM. Working Paper Series, 01/11, ESRC National Centre for Research Methods, <http://eprints.ncrm.ac.uk/1844/1/Review_of_methodological_innovations.pdf>

CHALFEN, R. \& RICH, M. (2007) Combining the Applied, the Visual and the Medical: Patients Teaching Physicians with Visual Narratives. In S. PINK (Ed.) Visual Interventions. Oxford: Berghahn. Pp 53-70.

GRAM-HANSSEN, K. (2008) Heat Comfort and Practice Theory: Understanding Everyday Routines of Energy Consumption. In KEN, T.G., TUKKER, A., VEZZOLI, C. \& CESCHIN, F. (Eds.), Proceedings $2^{\text {nd }}$ SCORE! conference: Sustainable Consumption and Production: Framework for Action. Brussels, Belgium.

GRAM-HANSSEN, K. (2011) Understanding Change and Continuity in Residential Energy Consumption. Journal of Consumer Culture, 11(1), 61-78.

HOSKINS, J.A. (2006) Agency, Objects and Biography. In TILLEY, C., KEANE, W., KÜCHLER, S., ROWLANDS, M. \& SPYER, P. (Eds.), Handbook of Material Culture (74-85). London: Sage.

INGOLD, T. (2000) The Perception of the Environment. London: Routledge.

INGOLD, T. (2007) Lines: A Brief History. London: Routledge. 
INGOLD, T. (2008) Bindings Against Boundaries: Entanglements of Life in an Open World. Environment and Planning A, 40, 1796-1810.

INGOLD, T. (2010), Footprints through the Weather-World: Walking, Breathing, Knowing. Journal of the Royal Anthropological Institute, 16, S121-S139. doi: 10.1111/j.1467-9655.2010.01613.x

LAMMER, C. (2007) Bodywork: Social Somatic Interventions in the Operating Theatres of Invasive Radiology. In PINK, S. (Ed.) Visual Interventions (91-116). Oxford: Berghahn.

MACDOUGALL, D. (2006) The Corporeal Image: Film, Ethnography, and the Senses. Princeton, NJ: Princeton University Press.

MASSEY, D. (2005) For Space. London: Sage.

MILLER, D. (2001) Home Possessions: Material Culture behind Closed Doors. Oxford: Berg.

MITCHELL, C. (2011) Doing Visual Research. London: Sage.

PINK, S. (2004) Home Truths: Gender, Domestic Objects and Everyday Life. Oxford: Berg. 192 pp, ISBN 1859736912

PINK, S. (2006) The Future of Visual Anthropology: Engaging The Senses. London: Routledge. 166 pp, ISBN 0415357659.

PINK, S. (2007) Doing Visual Ethnography: Images, Media and Representation in Research. Revised and expanded $2^{\text {nd }}$ edition. London: Sage. ISBN 0761960546

PINK, S. (2009) Doing Sensory Ethnography. London: Sage.

PINK, S. (2011a) Drawing With Our Feet (and Trampling the Maps): Walking With Video as a Graphic Anthropology. In INGOLD, T. (Ed.) Redrawing Anthropology. Farnham: Ashgate.

PINK, S. (2011b) Ethnography of the Invisible: How to 'See' Domestic and Human Energy. Ethnologia Europaea: Journal of European Ethnology (117-128)

PINK, S. (2012) Situating Everyday Life: Practices and Places, London: Sage.

RIGGINS, S.H. (1994) Fieldwork in the Living Room: An Autoethnographic Essay. In RIGGINS, S.H. (Ed.) The Socialness of Things: Essays on the Socio-Semiotics of Objects (101-147). New York: Mouton de Gruyter. 
SCHATZKI, T. (2001) Introduction: Practice Theory. In SCHATZKI, T., KNORR CETINA, K. \& VON SAVIGNY, E. (Eds.), The Practice Turn in Contemporary Theory (1-14). London: Routledge.

SHOVE, E. (2003) Comfort, Cleanliness and Convenience: The Social Organziation of Normality. Oxford: Berg.

SHOVE, E. \& WARDE, A. (2002) Inconspicuous Consumption: The Sociology of Consumption, Lifestyles, and the Environment. In DUNLAP, R.E., BUTTEL, F.H., DICKENS, P. \& GIJSWIJT, A. (Eds.), Sociological Theory and the Environment: Classical Foundations, Contemporary Insights (230-51). Oxford: Rowman \& Littlefield.

SUNDERLAND, P.L. \& DENNY, R.M. (2007) Doing Anthropology in Consumer Research. Walnut Creek, CA: Left Coast Press.

WILES, R., PAIN, H. \& CROW, G. (March 2010), Innovation in qualitative research methods: A narrative review. NCRM Working Paper Series, 03/10, ESRC National Centre for Research Methods,

<http://eprints.ncrm.ac.uk/919/1/innovation_in_qualitative_research_methods.pdf >

WILHITE, H. (2005) Why Energy Needs Anthropology. Anthropology Today, 21(3), $1-2$.

\footnotetext{
${ }^{\mathrm{i}}$ Sarah Pink is a Co-investigator for LEEDR, leading the Social Sciences strand of the project based in Social Sciences at Loughborough University. Kerstin Leder Mackley is a Research Associate for LEEDR, also working in the Social Sciences strand.
} 